\title{
Red lines and compromises: Mapping underlying complexities of Brexit preferences
}

\begin{abstract}
The political discourse is characterised by two opposing ideals of hard and soft Brexit. In this paper, we present evidence of attitudinal types that map neatly onto these archetypal views. The hard Brexit view is defined by issues that Eurosceptics prioritise, most prominently sovereignty. By contrast, Europhiles prioritise cooperation with Europe in terms of scientific collaboration and market access. However, attitudinal types are not either/or in the minds of the British public, and many prioritise all or none of the issues. Further, the two opposing positions together account for $37 \%$ of the public's view. That is, just over one third differentiate between the salient issues in ways congruent with political ideals. National identity plays a particular role in the socio-demographic profiles of these attitude types. Older people have a strong stance in any direction (sovereignty, cooperation, or both), but national identity is linked to differentiated positions (sovereignty only or cooperation only).
\end{abstract}

\section{Key words}

Public opinion; red lines; hard Brexit; soft Brexit; sovereignty; cooperation 


\section{Introduction and background}

Almost from the word go, the political discourse on the nature of the future relationship between the UK and the EU has been characterized by two opposing ideals of soft Brexit and hard Brexit. Though often ill-defined, the basic position of those advocating a soft Brexit would be one defined by the desire for a closer relationship with Europe, including continued tarifffree access to the single market, and staying inside the customs union. Advocates of the hard Brexit position, by contrast, would prefer to keep Europe at arm's length, and place more weight on matters relating to sovereignty, namely shaking off the jurisdiction of the European Court of Justice (ECJ) and regaining control of immigration. This is a prominent and divisive viewpoint within Theresa May's Cabinet, with Boris Johnson and Michael Gove making plain their 'ambition to be a fully independent self-governing country by the time of the next election', and Jacob Rees-Mogg declaring that 'If the ECJ still has jurisdiction we will not have left the EU... it is perhaps the most important red line in ensuring the leave vote is honoured'. On the other side, Chuka Umunna and other Europhiles in the Labour party have set out a list of preferences that includes access to the single market and close cooperation with other European countries on matters such as workers' rights and the environment ${ }^{1}$.

In terms of existing relationships between single nation-states and the European Union, there are a number of different possibilities, ranging from the soft 'Norway option' to the hard 'Canada option'. Norway is inside the single market and allows free movement of people, while Canada, by being outside the single market and customs union, retains extensive national control over EU immigration and is free from ECJ jurisdiction. Nonetheless, Canada has a bilateral agreement eliminating some trade barriers, and thus does not represent the hardest possible position. Options in between include Lichtenstein and Switzerland, although the former is unlikely, given statements from EU leaders such as Angela Merkel2. In terms of practical arrangements, then, the soft/hard dichotomy appears to be a false one: there is a spectrum of possibilities between those two extremes.

Emerging evidence suggests that boundaries between the soft and hard positions among the general public echo the spectrum of political arrangements, and are a matter of 'more or less' rather than 'yes or no'. One expectation we might have of the public's preferences for Brexit arrangements is that they would simply mirror the issues that were prominent in the EU referendum campaign. The Leave campaign centred on EU budget contributions and promised that a vote to leave the EU would be a vote to 'take back control'. The Remain campaign, on the other hand, focused on the economic costs to the country's GDP and household incomes in the event of leaving the EU.

Nonetheless, Hobolt and colleagues suggest that the preferences of Leavers and Remainers may not be as far apart as some might suggest, at least on some matters. The issues on which individuals from both sides are relatively consensual include greater sovereignty, access to the market, good trade deals, no (or a low) 'divorce bill', and continued rights for EU citizens already in the UK. There can be no doubt, however, that a divide has entered into the public consciousness, with three quarters of the British population identifying as either a Leaver $(38 \%)$ or a Remainer $(35 \%)^{3}$.

Accordingly, our first research questions are: 
1. Does public opinion neatly map onto the profiles of hard and soft Brexit? Is there just a single dimension of soft to hard Brexit, or is it more complex?

2. How divided are the Remainers and the Brexiteers in their attitudes towards possible Brexit deals? Where does the Remainer-Brexiteer line fall on the spectrum of soft to hard Brexit preferences?

Referendum vote choice, unsurprisingly, features as a prominent explanation for Brexit-related opinion 4 . One theory explaining why individuals voted to leave the EU is 'the left behind' thesis. This economic argument captures the idea that some sections of British society have not benefitted from modernisation and globalisation, which brought increased affluence, higher status, and better living standards to a greater number. Those who have remained in unskilled work with low incomes therefore increasingly feel resentment towards a political class that has become increasingly professionalised, and thus use their vote as a form of protest against the establishment 5 .

A further pathway linking economic vulnerability to Brexit attitudes is the perceived threat from immigrants for scarce resources. Immigrants are seen as direct competition for jobs and housing, and these perceptions may well be justified in some contexts. There is evidence that those on lower incomes, those with lower educational qualifications and the unemployed were all more likely to vote leave ${ }^{6}$.

However, the empirical support for the claim that attitudes toward Brexit have a purely economic basis is rather limited and mixed. On support for right-wing parties, is has been noted that 'the social profile is more complex than popular stereotypes suggest'7. Further, both political party manifestos and the voter profiles of party support suggest that economic issues have been decreasing in salience for decades ${ }^{8}$.

An alternative theory highlights the role of culture and values. Beginning in the 1960s, younger, more educated cohorts have increasingly become 'post-materialist' and cosmopolitan: being open towards other cultures, immigration and diversity, as well as embracing progressive views on gender roles, human rights, and sexual orientation. In addition to this set of linked issues, post-materialists hold more favourable views towards European integration. In response to this secular shift, a 'cultural backlash' has occurred among the older, less educated, (and male) sectors of society who begrudge their familiar traditional values being gradually squeezed to the margins of society The fact that older people were more likely to vote leave than younger people supports the idea of the cultural backlash. For the culturally left behind stratum of British society, EU membership represents a cultural threat ${ }^{9}$. Backing this cultural account, several studies show that strength of national identity (both Englishness and Britishness) is associated with the likelihood of voting leave, even after accounting for socio-demographic factors, although the effect of Englishness appears to be stronger 6 .

In sum, these theories of referendum vote choice can be grouped into economic and cultural dimensions. Two ideas lie behind the 'left behind' argument. First, the politically left behind used their vote choice to punish the political classes (and the liberal elite), due to feelings of resentment toward the increasingly elite politicians and political parties ${ }^{5}$. The second is that the economically left perceived economic threat from immigration, and voted to restrict immigration accordingly. By contrast, the cultural backlash idea posits that values (notions of what constitutes the good life) and identity (conceptions of nationhood) are the key issues. 
Our final research objective, therefore, is to seek to understand:

3. What light can public attitudes to Brexit negotiations shed on these theories of the Brexit vote? Do we find that the same explanations work, or do different explanations work for different underlying attitudes?

\section{Empirical strategy and Analysis}

To answer our research questions, we employ two primary analytic methods: Factor Analysis (FA) and Latent Class Analysis (LCA). These two methods are similar in their basic assumption that the object of enquiry is considered to be 'latent' which is to say that it cannot be directly observed but rather is inferred, statistically, from a set of manifest (i.e. observed) variables. The major difference between FA and LCA is that FA assumes the underlying variable(s) to be dimension-like in nature, while LCA assumes the underlying variable to be category-like. In taking on both methods, our aim is to fully explore the nature of the underlying attitudes, teasing out their complexity in order to push the existing paradigm.

We make use of the first wave of a new online panel study conducted by Kantar Public and fielded between July 10th and August 2nd 2017. Data are treated as cross-sectional and weighted by age, sex, region and country, working status, educational attainment, and voter turnout in both the EU referendum and the General Election of 2017. The sample size is 5,311. After a series of robustness checks, we drop 64 cases where we identified data quality issues and where the survey had been completed unfeasibly quickly.

\section{Descriptive Analysis}

We asked our survey respondents to imagine themselves at the negotiating table, with a question worded as follows... we want you to imagine that you are leading the UK's negotiations to leave the EU. We want to know what you think would be the best deal for Britain. So imagine you are at a deadlock in negotiations, when EU negotiators point to one part of the deal and say 'If you drop this demand, then we have a deal'. What would you be happy to drop or change in order to make a deal and what would be a 'red line' demand that you wouldn't compromise on even if it meant no deal at all? The issues we will be looking at cover: Sovereignty and law making, The Irish border, Immigration, The rights of UK nationals living in the EU, Exports to the EU, Scientific collaboration and Budget contributions

Some of the issues at the heart of the soft versus hard distinction are natural trade-offs. For example, remaining in the single market would necessarily involve acceding to EU market regulations, thereby relinquishing some control. However, the structure of our question does not force respondents to make trade-offs, meaning that they can chose both the single market and sovereignty if they please. And, as we go on to show, many do.

In Table 1 we show the weighted averages of responses to each of the seven items in the red line compromise battery (with rows summing to $100 \%$ ). The items are ordered by the percentage saying that this point of negotiation is a red line, with the highest being citizens' rights $(48 \%)$ and budget contributions (47\%), followed by sovereignty (39\%), free movement (37\%), collaboration (35\%) and access to EU markets (31\%). The border between Northern Ireland and Ireland seems to be considered less of a deal-breaker, with just $21 \%$ naming this as a red line. The border is also the item with the highest percentage of 'Can't say', suggesting that this may not have as much salience as the other issues on the table (on average across the UK). Our 
respondents are, on average, rather reluctant to drop demands completely, with $20 \%$ or fewer saying 'deal' on each item (with the exception of the border). Almost $40 \%$ report a willingness to budge on the key issue of access to the single market, a finding that perhaps lends weight to the growing consensus that Brexit is not primarily about the economy 7 .

Table 1 Percentages by item, red lines and compromises (ordered from highest red line percentage to lowest)

\begin{tabular}{|c|c|c|c|c|}
\hline & $\begin{array}{l}\text { Deal - I am } \\
\text { willing to } \\
\text { drop this } \\
\text { demand in } \\
\text { order to } \\
\text { reach a deal }\end{array}$ & $\begin{array}{l}\text { Budge }- \text { I am } \\
\text { not willing to } \\
\text { drop this } \\
\text { altogether but } \\
\text { I am willing to } \\
\text { negotiate }\end{array}$ & $\begin{array}{l}\text { Red Line - I } \\
\text { am not } \\
\text { willing to } \\
\text { negotiate or } \\
\text { drop this } \\
\text { demand }\end{array}$ & $\begin{array}{l}\text { Can't say - I } \\
\text { don't feel I } \\
\text { know } \\
\text { enough } \\
\text { about this } \\
\text { issue }\end{array}$ \\
\hline $\begin{array}{l}\text { UK Citizens resident in other EU } \\
\text { countries must have the same } \\
\text { rights as EU citizens in Britain }\end{array}$ & $19 \%$ & $22 \%$ & $48 \%$ & $11 \%$ \\
\hline $\begin{array}{l}\text { The UK must not be required to } \\
\text { make future contributions to the } \\
\text { EU budget }\end{array}$ & $15 \%$ & $26 \%$ & $47 \%$ & $12 \%$ \\
\hline $\begin{array}{l}\text { The EU must have no role at all in } \\
\text { UK law making }\end{array}$ & $16 \%$ & $33 \%$ & $39 \%$ & $12 \%$ \\
\hline $\begin{array}{l}\text { Free movement of all EU citizens to } \\
\text { the UK must be stopped }\end{array}$ & $19 \%$ & $35 \%$ & $37 \%$ & $9 \%$ \\
\hline $\begin{array}{l}\text { The UK and EU must agree to } \\
\text { continue collaborating on science, } \\
\text { research and technology initiatives }\end{array}$ & $20 \%$ & $31 \%$ & $35 \%$ & $14 \%$ \\
\hline $\begin{array}{l}\text { The UK must be given full access } \\
\text { for exporting goods and services to } \\
\text { the EU }\end{array}$ & $18 \%$ & $38 \%$ & $31 \%$ & $12 \%$ \\
\hline $\begin{array}{l}\text { The border between Northern } \\
\text { Ireland and the Republic of Ireland } \\
\text { must remain 'soft', without any } \\
\text { passport control between the UK } \\
\text { and the Republic of Ireland }\end{array}$ & $29 \%$ & $31 \%$ & $23 \%$ & $17 \%$ \\
\hline
\end{tabular}

Weighted; $N=5,247$

\section{Analysis 1: Brexit preferences as dimensions}

In the first instance, we used Factor Analysis to explore how the seven items above relate to more general latent dimensions (factors). For this part of the analysis, we code 'can't say' as missing, so that the variables are ordinal running from 1 (deal) to 3 (red line). The results suggest that two latent factors are sufficient to explain the patterns of responses to the seven specific items. In Table 2 we present the relationships (termed Factor Loadings) between the seven specific items and the two latent dimensions (further information on the model specification and selection can be found in the online supporting information that accompanies this article). 
Table 2 Results of Factor Analysis: Factor Loadings

\begin{tabular}{|l|c|c|}
\hline & Factor 1: Sovereignty Factor & Factor 2: Cooperative Factor \\
\hline Citizens' rights & 0.257 & $\mathbf{0 . 5 1 0}$ \\
\hline Budget contributions & $\mathbf{0 . 6 2 7}$ & 0.173 \\
\hline Sovereignty & $\mathbf{0 . 6 5 0}$ & 0.100 \\
\hline Free movement & $\mathbf{0 . 5 6 5}$ & 0.032 \\
\hline Scientific collaboration & 0.048 & $\mathbf{0 . 6 3 1}$ \\
\hline Market access & 0.153 & $\mathbf{0 . 6 1 6}$ \\
\hline Irish border & -0.047 & $\mathbf{0 . 3 2 7}$ \\
\hline
\end{tabular}

Rotated factor loadings; $N=3,472$

What emerges quite strikingly from the data is that the first latent factor relates to how close people come to the archetypical hard Brexit position. The items with highest factor loadings are sovereignty and budget contributions, followed by free movement. We label this factor the Sovereignty factor as a shorthand. The second factor, which we label the Cooperative factor, has the highest loadings on scientific collaboration and access to the single market. Confirming earlier research, ${ }^{4}$ we find that citizens' rights, though loading primarily on the cooperative factor, also loads moderately onto the sovereignty factor. The Irish border loads onto factor 2 but has a rather low loading score of 0.327 , suggesting that it is not a key element of this dimension of attitudes.

These two factors are not unrelated to each other; we find a correlation of 0.44 , implying a moderate tendency for people who score high on one factor to also score high on the other (and vice versa, to score low on both). In summary the Factor Analysis suggests that we cannot think of soft to hard Brexit in terms of a single dimension, but rather as two distinct but overlapping sub-dimensions. The moderate correlation implies that some individuals want to have their cake and eat it, wanting both sovereignty and cooperation. Others see the sub-dimensions as contradictory, valuing sovereignty rather than cooperation, for example. We now attempt to model these different types of attitude more explicitly using Latent Class Analysis.

\section{Analysis 2: Brexit preferences as types}

Unlike Factor Analysis, Latent Class Analysis identifies attitudinal clusters that best fit the data based on all the possible permutations of answer patterns. Latent classes can be intuitively thought of as groups of people (or types, or clusters) who have a tendency to answer the attitudinal questions in similar ways. The model fit statistics suggest that solutions with a greater number of classes are a better representation of the data, which in itself suggests a great deal of heterogeneity in public opinion. After weighing up the model fit statistics (with a preference for parsimony), we settle on the 7-class solution which is shown in Figure 1 (again, we provide further information on the model selection in the further information available online). The following attitude types emerge (ordered here, from high to low, by the percentage within that class who voted leave, a point we will come back to shortly).

1) The 'Hard Brexiters' make up $21 \%$ of the sample, and tend to be highly discriminating in their choice of red lines and compromises. People in this class are most likely to mention budget contributions and sovereignty, followed by free movement and citizens' rights. They 
are willing to either make a deal or negotiate on the Irish border, access to the single market and scientific collaborations

2) The 'Cake and Eat it' class is the largest at $29 \%$ of the sample. The main difference between classes 1 and 2 is that respondents in this class are far less discriminating in their choice of red lines. They are about equally likely to name sovereignty (65\%) and market access (70\%), suggesting that they do not view sovereignty and market access as a trade-off. Like the hard Brexit group, budget contributions are a red line for most, and the Irish border is deemed rather unimportant.

3) The 'Uncertain red-liners' make up just 3\% of the sample. Almost all respondents in this class name market access, collaboration, free movement and citizens' rights as red lines, but feel uninformed on the other issues.

4) The 'Deal Makers', $13 \%$ of the sample, are highly likely to want to make a deal on all 7 items. The deal-makers are quintessentially soft Brexiters, willing to drop all and any demands in order to reach a satisfactory deal with the EU.

5) The 'Tentative', $8 \%$ of the sample, contains a high prevalence of 'Can't Say'.

6) The 'Negotiators' make up $11 \%$ of the sample and are similar to the Deal-makers and Cake and Eat it classes in the indiscriminate nature of their attitudes. They are highly likely, across the board, to say we should budge in order to reach a good deal.

7) The 'Europhiles', finally, who make up $16 \%$ of the sample, have an attitudinal profile that is almost a mirror image of the Hard Brexiters. They too are highly discriminatory in their choices, but name their red lines as market access, the Irish border, citizens' rights and scientific collaborations.

Thus, the LCA provides a different representation of the data from the FA. However, we can demonstrate how the latent classes relate to the latent factors by plotting in figure 2 the position of five of the classes against the two sub-dimensions. (The two classes with high prevalence of 'Can't say' are not included, as we were unable to generate factor scores for these individuals). We find three classes on the diagonal, which is to say that that these are attitudinal clusters where scores on the Sovereignty factor and the Cooperative factor are closely in line. Those mentioning lots of red lines score high on the two dimensions, while those wanting to budge or make a deal score low on the two dimensions. These three classes have in common that respondents are not strongly discriminating between the different issues. This is in contrast to the opposing positions of the hard Brexiters and the Europhiles: these two groups make clear distinctions between the issues on the table, but the two groups prioritize, with the exception of citizens' rights, the opposite issues.

Turning now to our second research question: How divided are the Remain voters and the Leave voters in their attitudes towards possible Brexit deals? We can see that they are rather divided (see Figure 1), but only at the extremes of the attitudinal types. $75 \%$ of the Hard Brexiters voted leave, compared to just $21 \%$ of the Europhiles. It is classes 1 and 2 that have a majority of Leave over Remain, but the majority for Leave is far greater among those making sharp distinctions between the issues (75\%) than among those bestowing blanket red lines the Cake and Eat It class (58\%). The Hard Brexit class save their red lines for the classic hard Brexit issues, those featuring consistently throughout the campaign with regular reminders from the prominent Eurosceptic politicians. The Europhiles, however, name red lines,on those issues that keep us close to Europe regardless of whether they were prominent in the campaign: open borders, collaborations and citizens' rights. In our view, it is more accurate to categorize 
the Negotiators and the Deal-makers as fitting the soft Brexit ideals as their main concern appears to be getting a good deal, whereas the Europhiles actually represent a rather tough stance on the negotiations.

Figure 1 Latent Class Analysis: 7-class solution

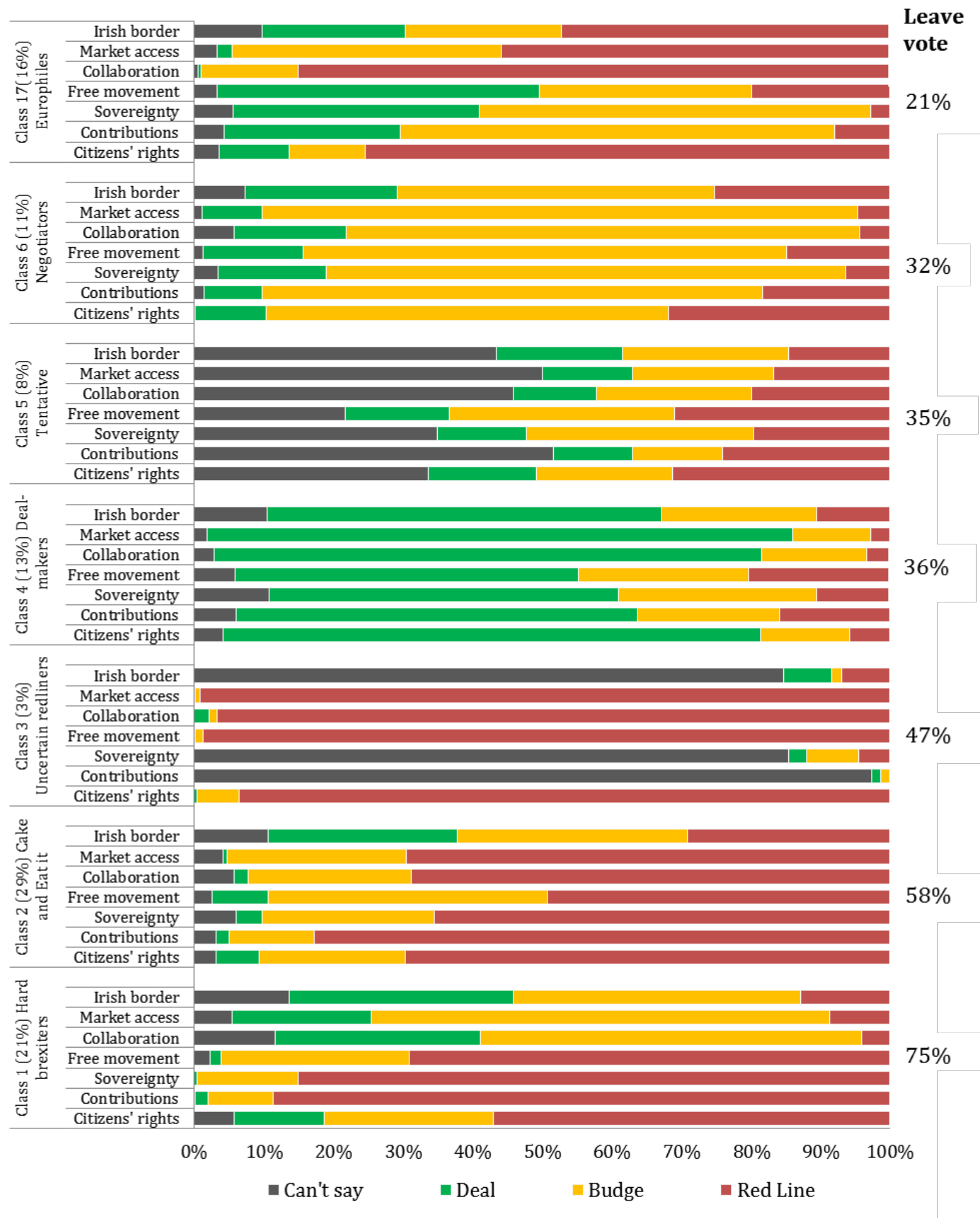

Results from preferred Latent Class model. The bars show probabilities of responses contingent on class membership. 
Figure 2 The position of five classes on the two sub-dimensions

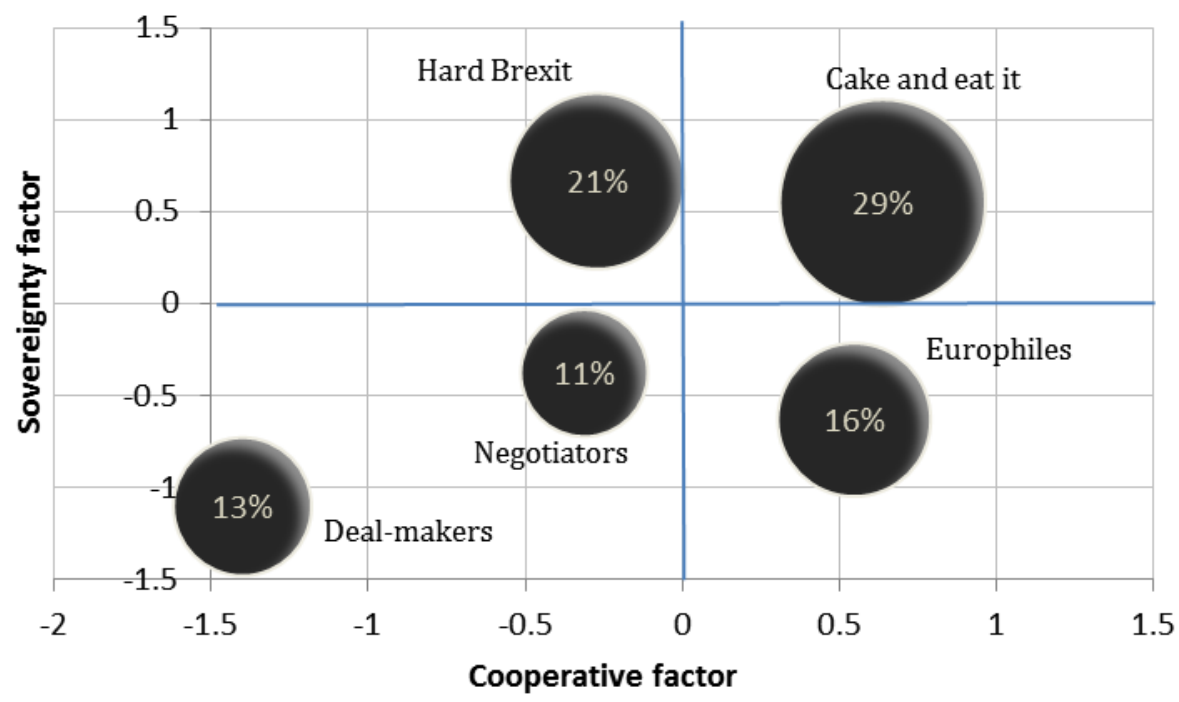

Bubble size represents the size of the latent class in terms of the proportion of respondents. The two factor scores run from -1.8 to +1.2 and have a mean of zero.

\section{Analysis 3: Socio-demographic profiles}

We operationalise the three major theories of Brexit opinion in the following way. Firstly, to test ideas of economic vulnerability, we include measures of perceived income situation, and occupation. Secondly, in order test the 'cultural backlash' idea we include age, education, and national identity. Third, we consider the 'political backlash' theory by including a measure of perceived political efficacy ('Politicians don't care about people like me').

Our statistical approach is as follows. We examine the effect of the explanatory measures, first on the two factor scores (which run from -1.8 to 1.2 with a mean of zero), and we then examine their effects on the odds of class membership. We compare the effects of being a Hard Brexiter versus a Europhile (i.e. the differentiating classes) to the effects of being Cake and Eat it versus the Negotiators and Deal-makers (i.e. the non-differentiating classes). We also compare to the Leave/Remainers based on vote choice.

We find that the two sub-dimensions look rather similar to each other in their demographic profiles in several ways, as shown in Figure 3. Older people, for example, tend to score higher on the Sovereignty factor, but also on the Cooperative factor. Other demographic factors that predict higher scores on both factors include being female and being in a financial situation below 'living comfortably', though compared to age the effect sizes are rather modest.

There is little evidence for a 'political backlash' with people who agree that politicians don't care scoring the same on Sovereignty as those who disagree with the statement.

On the other hand, we see divergence between the socio-demographic profiles of the two subdimensions, perhaps most clearly with respect to national identity. Identity has had a prominent place in explaining Brexit-related opinion (this being a proxy for peoples' cultural position), with a local and traditional outlook (Englishness) pitted against a more trans-national outlook 
(Britishness, Europeanness). Here we do find a set of opposites in our factors: Englishness is associated with higher Sovereignty scores, while Scottishness and Irishness are associated with lower Sovereignty scores and higher Cooperation scores. Strength of national identity conforms to this pattern of opposites, with stronger feeling linked to higher scores on the Sovereignty dimension, not the Cooperative.

Education, another indicator of one's cultural position, shows an interesting pattern of nonlinear effects. Those with mid-range qualifications score higher than those with no qualifications on both Sovereignty and Cooperation. At the degree level, however, we see a divergence. Degree holders have higher Cooperation scores but lower Sovereignty.

Turning now to the respective effects of different explanatory variables on class membership (Figure 4), it is perhaps unsurprising that the socio-demographic measures that distinguish the Hard Brexiters and the Europhiles closely mirror those distinguishing Leave and Remain voters. Leavers and Hard Brexiters have lower educational attainment, are older, and in terms of their national identities are more likely to be English than British but less likely to identify as Scottish, Irish or European.

However, the opposite 'diagonal', which compares the Cake and Eat it class to the other two non-differentiating classes, stands out as having a somewhat different socio-demographic profile. National identity has only weak effects here confirming our interpretation of the underlying sub-dimensions: identities are an important antecedent of those attitudinal profiles involving sharp distinctions between the issues. For those who treat all the issues on the negotiating table in the same way, national identity cannot explain who sets red lines, and who says 'budge' or 'deal'. 
Figure 3 Socio-demographic profiles of the latent factors

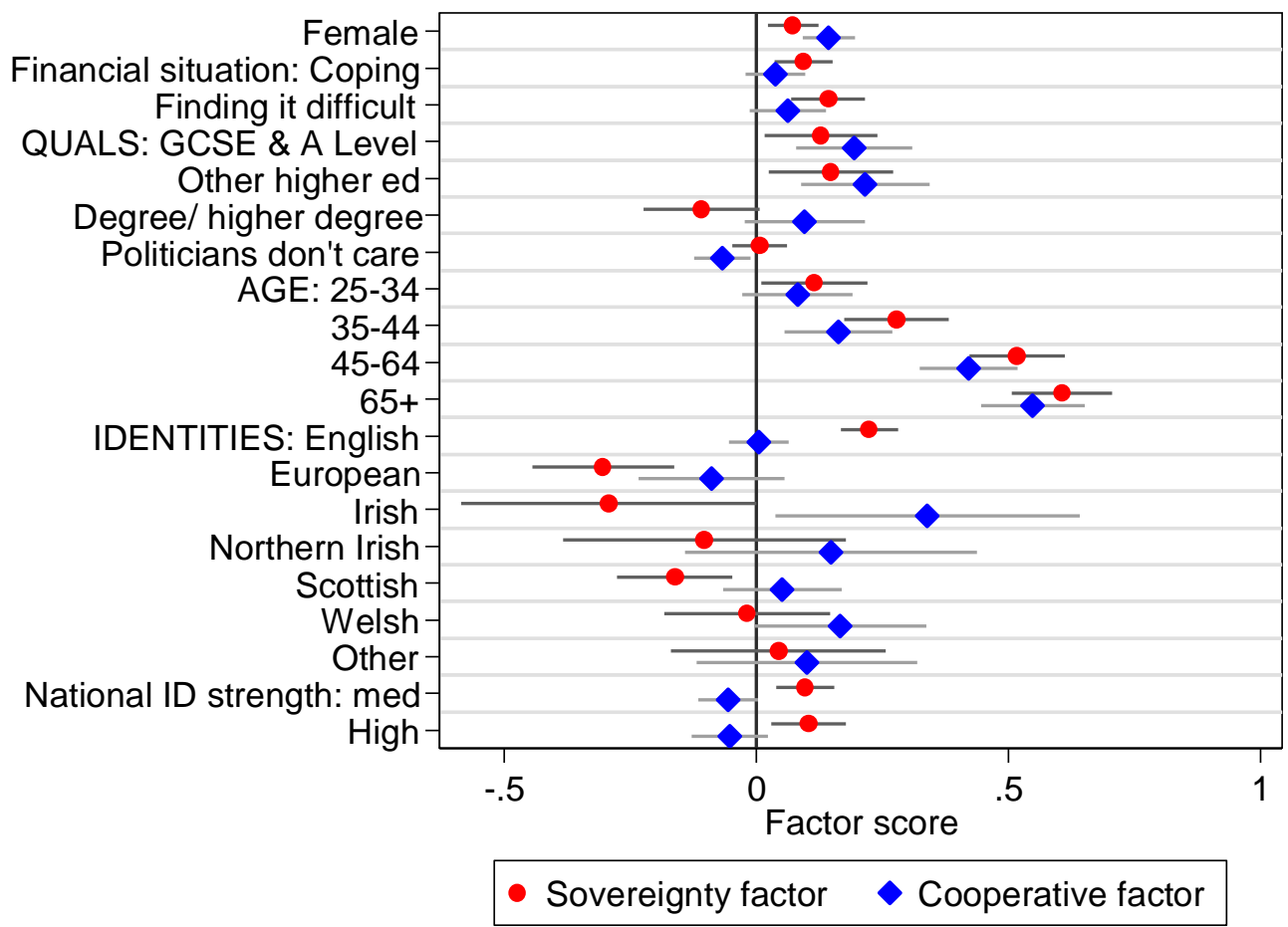

Plot of linear regression coefficients; outcomes are the two latent factors; References categories are Living comfortably (financial situation), No qualifications, 18-24 (age), British (national identity), Weak (national identity strength); bars show 95\% confidence intervals

Figure 4 Socio-demographic profiles of the latent classes compared to Leave/ Remain vote

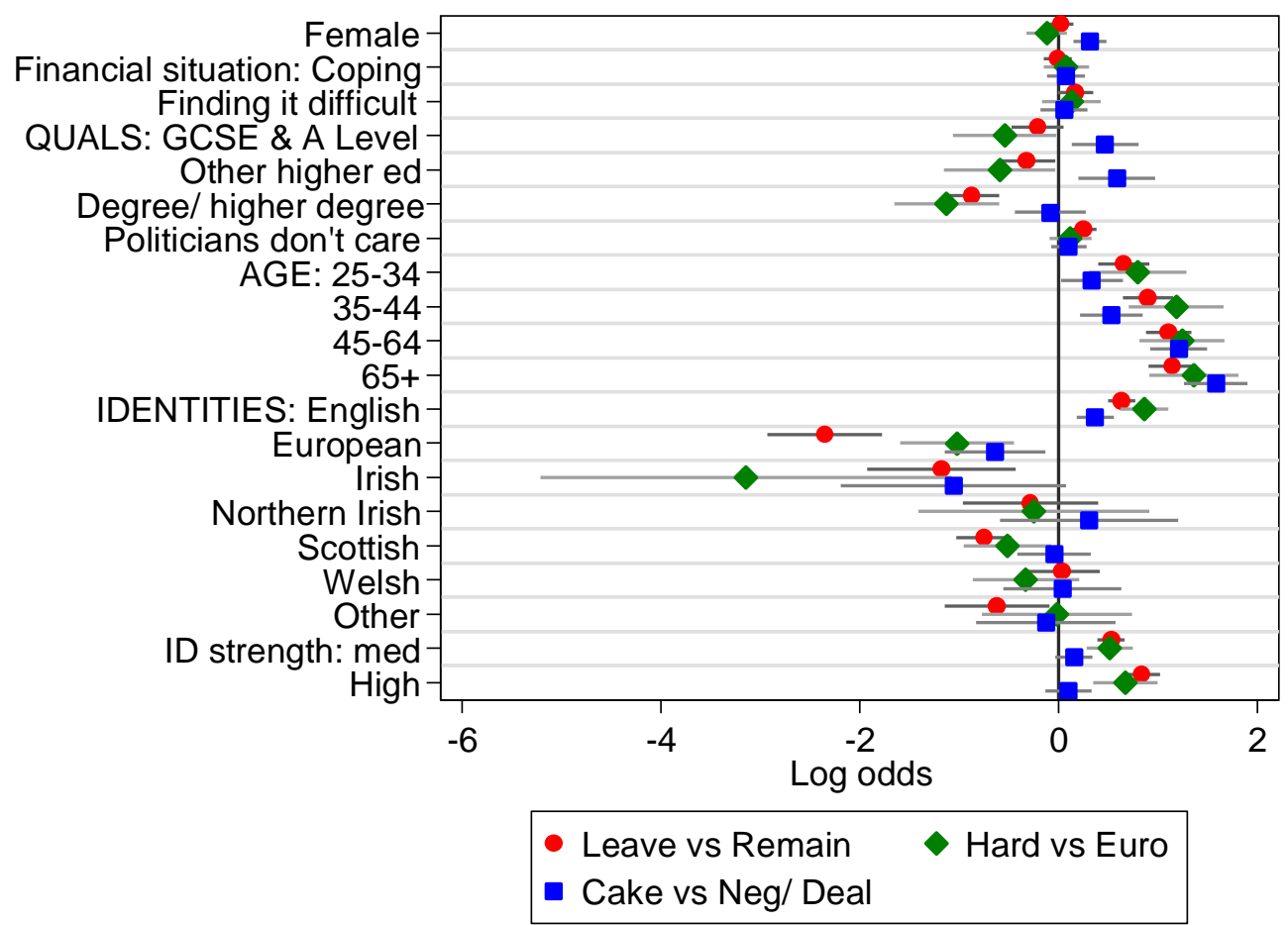


Plot of binary logistic regression coefficients; outcomes are pairs of latent classes and referendum vote; References categories are Living comfortably (financial situation), No qualifications, 18-24 (age), British (national identity), Weak (national identity strength); bars show 95\% confidence intervals

\section{Discussion and Conclusion}

Preferences for the type of relationship with the EU in post-Brexit Britain appear to be highly contested within the British public. We have presented evidence for attitudinal types that map rather neatly onto one or other of the two archetypal views that dominate the political and media discourse. The Sovereignty factor and the hard Brexit type are characterised by the same issues that exercise prominent Eurosceptics, namely sovereignty, budget contributions and free movement. The cooperation factor and the Europhile type prioritise scientific collaboration, citizens' rights and access to the single market. However, in contrast to the political discourse, these two positions are not a matter of either/ or in the minds of the British public and many prioritise all (the Cake and Eat it class) or none (the Deal-makers). Further, the opposing positions of Hard Brexit and Europhile account together for $37 \%$ of the public. That is, just over one third make distinctions in their choice of red lines that fit the political ideology.

The percentage who voted leave in the EU referendum tallies well with the two archetypal positions, with just $21 \%$ of the Europhiles voting leave, compared to $75 \%$ of the Hard Brexiters. The vote split among the more middling attitude types, on the other hand, is much closer to 50 / 50. Among the largest cluster, the Cake and Eat it group, 58\% voted to leave. The complexity of the number of factors involved (immigration, the single market, the Irish border, citizens' rights etc.) means that vote choice may, for some, have been in spite of policy preferences, not because of them.

In terms of the major theories of Brexit vote choice, we find (as have others ${ }^{7}$ ) that the evidence for the cultural backlash theory is more convincing than evidence for other types of backlash. In our models of Brexit preferences, we find rather modest effects for both subjective income position and for feeling that politicians 'don't care about people like me'. Thus, the evidence is limited in support of the idea that Brexit preferences are driven by economic threat and by being politically left behind by the increasingly elite political classes. We concur with prior studies showing that cultural factors including education and national identity appear to be the crucial points that demarcate sectors of the British public ${ }^{7}{ }^{6}$. In terms of national identity, our findings suggest that Englishness is associated with a preference for national sovereignty, being perhaps a proxy for a more traditional, and more local (less global) outlook. Irishness, Scottishness and Europeanness are instead more linked to a trans-national outlook, and people with these identities strongly favour cooperation with the EU.

National identity in our view plays a particular role in the socio-demographic profiles of public opinion. While age is linked with a strong stance in any direction (sovereignty, cooperation, or both), national identity, on the other hand, is more strongly linked to differentiated positions (sovereignty only or cooperation only). 


\section{Notes}

${ }^{1}$ Walters and Owen 'Boris and Gove's plot to 'hijack' Number 10 exposed: Menacing secret memo to Theresa May dictating terms for a hard Brexit triggers new Cabinet rift' Mail Online 13 ${ }^{\text {th }}$ November 2017 http://www.dailymail.co.uk/news/article-5073567/Boris-Gove-s-plothijack-Number-10-exposed.html; Neilan ‘Boris Johnson rows back on Brexit red line after Theresa May confirms ECJ jurisdiction during transition' City AM 9th October 2017 http://www.cityam.com/273548/boris-johnson-rows-back-brexit-red-line-after-theresa-may; Reuters 'UK opposition leader Corbyn wants close relationship with Europe' Reuters $8^{\text {th }}$ December 2017 https://uk.reuters.com/article/uk-britain-eu-corbyn/uk-opposition-leadercorbyn-wants-close-relationship-with-europe-idUKKBN1E21NS; $\underline{\text { Stephen Doughty As Labour }}$ politicians, we reject a hard-right Brexit, and defend the single market. The Guardian 20th June

\section{7 https://www.theguardian.com/commentisfree/2017/jun/20/end-austerity-uk-single-}

\section{market-theresa-may-brexit}

${ }^{2}$ Carl N. 'What sort of Brexit deal does the British public want: A review of the evidence so far'. Centre for Social Investigation: Nuffield College 2017.

${ }^{3}$ Hobolt SB. 'The Brexit vote: a divided nation, a divided continent'. Journal of European Public Policy 2016; 23:1259-77; Hobolt SB, Leeper T. 'The British are indifferent about many aspects of Brexit, but Leave and Remain voters are divided on several key issues'. LSE Blog. London: London School of Economics 2017.

${ }^{4}$ e.g. Hobolt SB, Leeper T. 'The British are indifferent about many aspects of Brexit, but Leave and Remain voters are divided on several key issues'. LSE Blog. London: London School of Economics 2017; Curtice J. 'What do voters want from Brexit?' NatCen Social Research 2017.

${ }^{5}$ Heath O. Policy representation, social representation and class voting in Britain. Brit J Polit Sci $2015 ; 45: 173-93$.

${ }^{6}$ Hobolt SB. 'The Brexit vote: a divided nation, a divided continent'. Journal of European Public Policy 2016; 23:1259-77; Carl N. 'CSI Brexit 3: National Identity and Support for Leave versus 
Remain'. Centre for Social Investigation 2017.; Henderson A, Jeffery C, Liñeira R, et al. ‘England, Englishness and Brexit'. The Political Quarterly 2016; 87:187-99.

${ }^{7}$ Antonucci L, Horvath L, Kutiyski Y, et al. 'The malaise of the squeezed middle: Challenging the narrative of the 'left behind' Brexiter'. Competition \& Change 2017; Curtice J. 'A question of culture or economics? Public attitudes to the European Union in Britain'. The Political Quarterly 2016;87:209-18.; Mudde (2007) cited in Inglehart R, Norris P. 'Trump, Brexit, and the rise of populism: Economic have-nots and cultural backlash'. 2016.

8 Inglehart R, Norris P. 'Trump, Brexit, and the rise of populism: Economic have-nots and cultural backlash'. 2016.

${ }^{9}$ McLaren LM. 'Public support for the European Union: cost/benefit analysis or perceived cultural threat?' The Journal of Politics 2002; 64:551-66. 